\title{
Editorial: Multiple Herbicide-Resistant Weeds and Non-target Site Resistance Mechanisms: A Global Challenge for Food Production
}

\begin{abstract}
Joel Torra ${ }^{1}$, María Dolores Osuna ${ }^{2}$, Aldo Merotto ${ }^{3}$ and Martin Vila-Aiub ${ }^{4 *}$
${ }^{1}$ Department d'Hortofructicultura, Botànica i Jardineria, Agrotecnio-CERCA Center, Universitat de Lleida, Lleida, Spain, ${ }^{2}$ Center for Scientific and Technological Research of Extremadura (CICYTEX), Agrarian Research Center "Finca La Orden" Valdesequera, Badajoz, Spain, ${ }^{3}$ Department of Crop Science, Faculty of Agronomy, Federal University of Rio Grande Do Sul (UFRGS), Porto Alegre, Brazil, ${ }^{4}$ Department of Ecology, IFEVA -CONICET, Faculty of Agronomy, University of Buenos Aires (UBA), Buenos Aires, Argentina
\end{abstract}

Keywords: cross-resistance, cytochrome P450 monooxygenase (CYP450), enhanced herbicide metabolism, glutathione-S-transferase (GST), glyphosate, rapid necrosis

Editorial on the Research Topic

OPEN ACCESS

Edited by:

Luigi Lucini,

Catholic University of the Sacred

Heart, Italy

Reviewed by:

Kerry Charles Harrington,

Massey University, New Zealand

Carmen Arena,

University of Naples Federico II, Italy

*Correspondence:

Martin Vila-Aiub

vila@ifeva.edu.ar

Specialty section:

This article was submitted to

Crop and Product Physiology,

a section of the journal

Frontiers in Plant Science

Received: 23 August 2021 Accepted: 29 September 2021 Published: 28 October 2021

Citation:

Torra J, Osuna MD, Merotto A and Vila-Aiub M (2021) Editorial: Multiple Herbicide-Resistant Weeds and

Non-target Site Resistance

Mechanisms: A Global Challenge for

Food Production.

Front. Plant Sci. 12:763212.

doi: 10.3389/fpls.2021.763212
Multiple Herbicide-Resistant Weeds and Non-target Site Resistance Mechanisms: A Global Challenge for Food Production

\section{EVOLUTION OF MULTIPLE SURVIVAL MECHANISMS}

The acquired inheritable trait of plants to survive and reproduce under herbicide exposure is defined as resistance. Herbicide resistance is an extraordinary example of adaptive evolution in weed species infesting agroecosystems with clear detrimental consequences on agriculture sustainability around the globe (Palumbi, 2001; Llewellyn et al., 2016). Multiple herbicide resistance is a compelling evolutionary process in which distinct survival mechanisms are present in a population or are combined within single plants, each endowing resistance to dissimilar site of action herbicides (Hall et al., 1994; Gaines et al., 2020). These multiple mechanisms may involve either target site (TSR) or non-target site resistance (NTSR) mechanisms or any combination endowing multiple resistance. Multiple resistance can evolve through unique events that sequentially select for resistance alleles within single plants and/or genetic exchange of independently evolved resistance mutations through pollen outcrossing among plants within or between populations. Regardless of the driving factor, the ultimate result is the stack of various distinct survival mechanisms at the plant and/or population level endowing broad resistance to multiple herbicides of dissimilar chemistries.

Genetic variability and reproductive biology of weed species are the most important factors that define the likelihood of multiple resistance evolution. Lolium rigidum, Alopecurus myosuroides, Raphanus raphanistrum, and Amaranthus spp. are among the weed species with the most remarkable ability to evolve multiple resistance through eco-evolution of TSR and NTSR mechanisms (Hall et al., 1997; Cocker et al., 1999; Walsh et al., 2004; Owen et al., 2014, 2015; Schultz et al., 2015; Han et al., 2016; Tétard-Jones et al., 2018). For instance, resistance due to reduced glyphosate and paraquat translocation co-evolving with an ACCase target site mutation has been identified in a single L. rigidum population ( $\mathrm{Yu}$ et al., 2007), whereas other patterns of multiple resistance in this species reflect the presence of enhanced CYP-450 herbicide metabolism coexisting with ACCase, ALS, $\alpha$-tubulin, and/or EPSPS point mutations 
(Burnet et al., 1994a,b; Tardif and Powles, 1994; Neve et al., 2004; Han et al., 2016, 2021; Chen et al., 2018, 2020a). Another striking example of multiple resistance is found in $A$. tuberculatus populations where $P P O, A L S$, and EPSPS target site mutations have been identified co-evolving with enhanced metabolism of PSII and HPPD inhibiting herbicides (Schultz et al., 2015).

Novel resistance mechanisms in weeds have been identified recently although some were thought unlikely to evolve. For instance, glyphosate resistance is possible through aldoketoreductase (AKR)-based metabolism (Pan et al., 2019), up-regulation of an $\mathrm{ABC}$ membrane transporter pumping out glyphosate outside the cell (Pan et al., 2021) and programmed cell death causing rapid necrosis (Van Horn et al., 2018). Likewise, 2,4-D resistance due to either CYP-450 based metabolism (Giacomini et al., 2020), a double point mutation (Leclere et al., 2018) or 9-codon deletion in an auxin transcriptional repressor (Figueiredo et al., 2021), or rapid necrosis (De Queiroz et al., 2020) have also been reported. These recent findings highlight that herbicide selection for many survival mechanisms will occur and increase the chances for plants to harbor multiple resistance mechanisms. Multiple herbicide resistance highlights the concurrent dynamic spread of multiple resistance alleles in weeds which exposes a serious threat to productivity of current cropping systems.

\section{RECENT ADVANCES IN NTSR MECHANISMS}

Mechanisms that can contribute to NTSR are complex and involve several different gene types and families. This molecular and genetic complexity makes the identification of particular genes involved in NTSR difficult. Recent advances in this area have been the identification of putative NTSR genes contributing to enhanced herbicide metabolism (EHM).

The latest finding has been the elucidation for the first time that up-regulation of the AKR enzyme contributes to glyphosate resistance in Echinochloa colona, by degrading glyphosate to its metabolite, aminomethylphosphonic acid (AMPA; Pan et al., 2019). This discovery further supports results published in this Research Topic, showing glyphosate metabolism in an E. crusgalli population from Portugal (Vázquez-García, Rojano-Delgado et al.). The identification of CYP-450 genes (phase I) that can degrade herbicides from different sites of action (SoA) has been carried out recently. CYP81A subfamily has been shown to metabolize herbicides from at least five chemically unrelated groups, both in L. rigidum and E. phyllopogon (Dimaano et al., 2020; Han et al., 2021). Unraveling which SoA and chemical herbicide families individual CYPs can metabolize, and their identification in different $\mathrm{R}$ species could help predicting metabolic-based cross-resistance patterns and thus assist in chemical options for weed management practices.

CYP-450 has been shown to endow herbicide resistance in broadleaf weed species too, as reported for Glebionis coronia to ALS inhibitors in this Research Topic (Hada et al.). It is worth mentioning studies confirming that CYP-450 is involved in 2,4D metabolism in A. tuberculatus (Figueiredo et al., 2018) and
Papaver rhoeas (Torra et al., 2021). Moreover, in P. rhoeas, the same CYP-450 has been shown to confer cross-resistance to both 2,4-D and imazamox in several R populations (Torra et al., 2021).

Phase II herbicide metabolism mainly involves conjugation to GSH mediated by GSH S-transferases (GSTs). Metabolic resistance to VLCFA inhibiting herbicides such as flufenacet and pyroxasulfone in Alopecurus myosuroides and L. rigidum populations is possible due to enhanced GST-mediated metabolism via differentially expressed GSTs (Dücker et al., 2019, 2020; Goggin et al., 2021). In this Research Topic, empirical evidence of herbicide metabolism via CYP-450 is provided in three articles (Yanniccari, Gigón et al.; Chen et al.; Hada et al.), of GST in two (Wang et al.; Rangani et al.), and of both CYP-450 and GST in five studies (Scarabel et al.; Shyam et al.; Suzukawa et al.; Franco-Ortega et al.; Torra et al.).

All types of resistance mechanisms can get stacked in $\mathrm{R}$ plants, both TSR and NTSR, but also different genes conferring EHM. Several studies have reported over-expression of many genes in NTSR plants compared to $\mathrm{S}$ ones, also including those encoding for degrading enzymes such as CYP-450 and GST (Gaines et al., 2020). However, this does not necessarily imply a process of recurrent selection and the concomitant slow accumulation of metabolic resistance genes in a $\mathrm{R}$ population. There is evidence that differentially expressed genes responsible for EHM could be under genomic co-expression clusters or across long chromosomal intervals (Giacomini et al., 2020). One major implication of this clustering is the likelihood of a shared mechanism of gene regulation for these regions with NTSR genes. Therefore, potentially, a single gene, that is, a single resistance mechanism, could be responsible of the reported over-expression of several genes involved in EHM and NTSR.

In this Research Topic, Franco-Ortega et al. suggested that plant responses to biotic and abiotic stressors are integrally linked to NTSR-based herbicide resistance mechanisms. Regulation of gene expression involved in stress-response and NTSR is probably a complex process but may include herbicideresponsive genes. Recently, HPPD-inhibiting herbicide responsive genes have been found in A. tuberculatus, with little overlap in gene expression patterns between $\mathrm{R}$ and $S$ genotypes bringing out dynamic differences in response to herbicide treatment (Kohlhase et al., 2019). Similarly, a contributing article in the present Research Topic, points out that S-metolachlor (VLCFA inhibitor) can further increase the expression of two GSTs in R plants (Rangani et al.).

Differential herbicide translocation between $S$ and $R$ plants constitutes another set of NTSR mechanisms. Membrane carrier proteins (ABC family) are already being unveiled and suggested to be involved in phase III of EHM (Gaines et al., 2020). Although reduced glyphosate translocation was described as a resistance mechanism long ago, only recently the first glyphosate cell membrane carrier has been identified (ABCC-type transporter) conferring glyphosate resistance in E. colona (Pan et al., 2021). Active root exudation as a NTSR mechanism has been recently reviewed by Ghanizadeh and Harrington (2020). This mechanism could contribute to imazamox resistance in Euphorbia heterophylla (Rojano-Delgado 
et al., 2019) and MCPA resistance in Raphanus raphanistrum (Jugulam et al., 2013).

\section{Rapid Necrosis: An Intriguing Mechanism of Herbicide Resistance}

A fast and localized effect of glyphosate and 2,4-D has been identified in Ambrosia trifida (Brabham et al., 2011) and Conyza sumatrensis (De Queiroz et al., 2020). This phenomenon has been called rapid necrosis ( $\mathrm{RN})$, and was primarily proposed as Phoenix resistance (Gressel, 2009) as apparent "dead" plants were able to regrow a few days after herbicide treatment. The physiological basis of this surviving mechanism is unknown and thus, the classification of RN as TSR or NTSR is difficult. The RN caused by 2,4-D may be related to defective Aux/IAA repressors, TIR1/AFB receptors and ARF transcription factors and in that case would be classified as TSR since these proteins are directly related to the 2,4-D action. Exogenous application of aromatic amino acids decreased $\mathrm{RN}$ in A. trifida caused by glyphosate (Moretti et al., 2018), indicating a potential TSR mechanism of resistance.

In both 2,4-D and glyphosate cases, a potential reduced herbicide translocation resistance mechanism could be related to $\mathrm{ABC}$ transporters (Pan et al., 2021), however, alterations in translocation and cell exclusion resulting in 2,4-D and glyphosate resistance were not identified with the RN phenotype. Some evidence suggests that programmed cell death may be caused not only by pathogens as originally discovered but also triggered by other biotic and abiotic stresses such as herbicides (Burke et al., 2020). Several studies have reported the influence of environmental effects on the occurrence and variability of RN (Harre et al., 2018; De Queiroz et al., 2020), which highlight the difficulties of studying $\mathrm{RN}$ under the variable conditions found in the field and experimental conditions. Distinguishing the biochemical processes that cause $\mathrm{RN}$ from those that are the consequence of $\mathrm{RN}$ is needed to better understand this intriguing herbicide resistance mechanism.

\section{Contributions in the Research Topic}

Contributions in this Research Topic reported both TSR and NTSR mechanisms. Eight out of 13 articles reported mechanisms of TSR nature (all substitutional mutations), which in some cases can confer cross-resistance to different herbicide chemistries within the same SoA (Scarabel et al.; Vázquez-García, Alcántara-De La Cruz et al.; Yanniccari, Gigón et al.; Hada et al.; Torra et al.). Among these contributions, we shall highlight those reporting multiple-resistance through the accumulation of several substitutional point mutations in different herbicide target enzymes involving ALS, ACCase and EPSPS inhibitors (Scarabel et al.; Vázquez-García, Alcántara-De La Cruz et al.).

In relation to NTSR mechanisms, three contributions reported about herbicide differential absorption and translocation (Suzukawa et al.; Vázquez-García, Rojano-Delgado et al.; Yanniccari, Vázquez-García et al.), whereas most of them (11 out 13) documented cross-resistance due to some level of EHM. It is also remarkable that seven contributions demonstrated the co-evolution of TSR and NTSR mechanisms at both plant and population level.
Resistance to ALS, ACCase, and EPSPS inhibiting herbicides are the most reported cases in this Research Topic, with 8, 7, and 5 contributions, respectively, which agrees with the SoA herbicides most related to herbicide resistance worldwide (Heap, 2021). Resistance to pre-emergence herbicides in different cropping systems is reported, as multiple resistance in combination to the three previously mentioned post-emergence SoA herbicides. Resistance to microtubule assembly (Suzukawa et al.; Chen et al.; Franco-Ortega et al.), VLCFA (Suzukawa et al.; Rangani et al.; Torra et al.), PSII (Shyam et al.; Franco-Ortega et al.; Torra et al.), synthetic auxins (Shyam et al.; Suzukawa et al.; Franco-Ortega et al.; Torra et al.), and both PPO and HPPD in a single six-way-resistant Palmer amaranth (Amaranthus palmeri) population (Shyam et al.) are contributions in this Special Issue.

Ten out of 13 contributions reported on herbicide resistance in grass weed species, and three in broadleaf weeds. Lolium ssp. is the most reported genus in the Research Topic (six articles), followed by A. myosuroides and Bromus ssp. (2), and E. crusgalli and Beckmannia syzigachne (1). Among dicots, two articles reported on the global invasive weed species A. palmeri (Shyam et al.; Rangani et al.) and one contribution on Glebionis coronaria (Hada et al.).

\section{CURRENT RESEARCH GAPS AND PROSPECTS}

(1) Multiple herbicide resistance may result from co-evolution of both NTRS and TSR mechanisms (Vila-Aiub et al., 2005; Powles and Yu, 2010; Bostamam et al., 2012; Gherekhloo et al., 2017; Peterson et al., 2018; Cao et al., 2021). An intriguing question is the evolutionary and ecological consequences of the interaction between NTSR and TSR mechanisms in protecting single plants from herbicide damage (Raymond et al., 1989). For instance, point resistance mutations co-existing with up-regulation of herbicide metabolism (EHM by CYP-450 or GST), both endowing resistance to herbicides targeting the same SoA are ubiquitous in resistant weeds (Tardif and Powles, 1994; Chen et al., 2020a,b). Do these resistance mechanisms combine their effects on plant protection in an additive or multiplicative mode? Would it be possible for a single mechanism to endow the maximum protection level making the addition of a second mechanism an ecological redundancy?

(2) Improved understanding of the biology of plant systems will benefit the understanding of gene regulation of NTSR and the effects of environmental factors on the evolution of herbicide resistance. Further studies related to epigenetic regulation caused by direct or indirect herbicide effects will further increase our understanding of herbicide resistance. The NTSR mechanisms associated with EHM are dependent on a complex gene regulation and we are currently just discovering the final players of a large network. Advances on CYP-450 and GST gene identification as well as their regulation and crystallographic 
information will reveal a fascinating environmental-plantherbicide interaction system.

(3) Current recommendations for pesticide resistance prevention are based on rotation and mixing of different SoA pesticides (Bourguet et al., 2013; Baym et al., 2016). However, rotation and/or mixing of herbicides resulting in a similar selection pressure for a particular resistance mechanism (e.g., EHM) will increase the risk of resistance evolution (Comont et al., 2020). The advances in the knowledge of NTSR mechanisms will be necessary for making resistance management decisions involving the use of herbicides targeting different metabolic networks, assuming it is possible to avoid development of some of these resistance mechanisms by modifying management.

\section{REFERENCES}

Baym, M., Stone, L. K., and Kishony, R. (2016). Multidrug evolutionary strategies to reverse antibiotic resistance. Science 351:aad3292. doi: $10.1126 /$ science.aad 3292

Bostamam, Y., Malone, J., Dolman, F. C., Boutsalis, P., and Preston, C. (2012). Rigid ryegrass (Lolium rigidum) populations containing a target site mutation in EPSPS and reduced glyphosate translocation are more resistant to glyphosate. Weed Technol. 60, 474-479. doi: 10.1614/WS-D-11-00154.1

Bourguet, D., Delmotte, F., Franck, P., Guillemaud, T., Reboud, X., Vacher, C., et al. (2013). Heterogeneity of selection and the evolution of resistance. Trends Ecol. Evol. 28, 110-118. doi: 10.1016/j.tree.2012.09.001

Brabham, C. B., Gerber, C. K., and Johnson, W. G. (2011). Fate of glyphosateresistant giant ragweed (Ambrosia trifida) in the presence and absence of glyphosate. Weed Sci. 59, 506-511. doi: 10.1614/WS-D-11-00050.1

Burke, R., Schwarze, J., Sherwood, O. L., Jnaid, Y., Mccabe, P. F., and Kacprzyk, J. (2020). Stressed to death: the role of transcription factors in plant programmed cell death induced by abiotic and biotic stimuli. Front. Plant Sci. 11:1235. doi: 10.3389/fpls.2020.01235

Burnet, M. W. M., Christopher, J. T., Holtum, J. A. M., and Powles, S.B. (1994a). Identification of 2 mechanisms of sulfonylurea resistance within one population of rigid ryegrass (Lolium rigidum) using a selective germination medium. Weed Sci. 42, 468-473. doi: 10.1017/S0043174500076785

Burnet, M. W. M., Hart, Q., Holtum, J. A. M., and Powles, S.B. (1994b). Resistance to nine herbicide classes in a population of rigid ryegrass (Lolium rigidum). Weed Sci. 42, 369-377. doi: 10.1017/S0043174500076645

Cao, Y., Wei, S., Huang, H., Li, W., Zhang, C., and Huang, Z. (2021). Target-site mutation and enhanced metabolism confer resistance to thifensulfuron-methyl in a multiple-resistant redroot pigweed (Amaranthus retroflexus) population. Weed Sci. 69, 161-166. doi: 10.1017/wsc.2020.93

Chen, J., Chu, Z., Han, H., Goggin, D. E., Yu, Q., Sayer, C., et al. (2020a). A Val202-Phe $\alpha$-tubulin mutation and enhanced metabolism confer dinitroaniline resistance in a single Lolium rigidum population. Pest Manag. Sci. 76, 645-652. doi: $10.1002 /$ ps.5561

Chen, J., Huang, H., Wei, S., Cui, H., Li, X., and Zhang, C. (2020b). Glyphosate resistance in Eleusine indica: EPSPS overexpression and P106A mutation evolved in the same individuals. Pesticide Biochem. Physiol. 1:14. doi: 10.1016/j.pestbp.2020.01.014

Chen, J., Yu, Q., Owen, M., Han, H., and Powles, S. (2018). Dinitroaniline herbicide resistance in a multiple-resistant Lolium rigidum population. Pest Manag. Sci. 74, 925-932. doi: 10.1002/ps.4790

Cocker, K. M., Moss, S. R., and Coleman, J. O. D. (1999). Multiple mechanisms of resistance to fenoxaprop-P-ethyl in United Kingdom and other European populations of herbicide-resistant Alopecurus myosuroides (Black-Grass). Pesticide Biochem. Physiol. 65, 169-180. doi: 10.1006/pest. 1999.2439

Comont, D., Lowe, C., Hull, R., Crook, L., Hicks, H. L., Onkokesung, N., et al. (2020). Evolution of generalist resistance to herbicide mixtures

\section{AUTHOR CONTRIBUTIONS}

All authors conceived and wrote this Editorial contribution for the Research Topic Multiple Herbicide-Resistant Weeds and Nontarget Site Resistance Mechanisms: A Global Challenge for Food Production.

\section{ACKNOWLEDGMENTS}

We acknowledge the support of the Editorial Board of Frontiers in Plant Science. Thank you for the feedback and comments provided from peer-reviewers. JT acknowledges support from the Spanish Ministry of Science, Innovation, and Universities (grant Ramon y Cajal RYC2018-023866-I). reveals a trade-off in resistance management. Nat. Commun. 11, 1-9. doi: 10.1038/s41467-020-18079-3

De Queiroz, A. R., Delatorre, C. A., Lucio, F. R., Rossi, C. V., Zobiole, L. H., and Merotto, A. (2020). Rapid necrosis: a novel plant resistance mechanism to 2, 4-D. Weed Sci. 68, 6-18. doi: 10.1017/wsc.2019.65

Dimaano, N. G., Yamaguchi, T., Fukunishi, K., Tominaga, T., and Iwakami, S. (2020). Functional characterization of cytochrome P450 CYP81A subfamily to disclose the pattern of cross-resistance in Echinochloa phyllopogon. Plant Mol. Biol. 102, 403-416. doi: 10.1007/s11103-019-00954-3

Dücker, R., Parcharidou, E., and Beffa, R. (2020). Flufenacet activity is affected by GST inhibitors in blackgrass (Alopecurus myosuroides) populations with reduced flufenacet sensitivity and higher expression levels of GSTs. Weed Sci. 68, 451-459. doi: 10.1017/wsc.2020.54

Dücker, R., Zöllner, P., Lümmen, P., Ries, S., Collavo, A., and Beffa, R. (2019). Glutathione transferase plays a major role in flufenacet resistance of ryegrass (Lolium spp.) field populations. Pest Manag. Sci. 75, 3084-3092. doi: $10.1002 /$ ps.5425

Figueiredo, M. R., Kuepper, A., Malone, J. M., Petrovic, T., Figueiredo, A. B. T., Campagnola, G., et al. (2021). An in-frame deletion mutation in the degron tail of auxin co-receptor IAA2 confers resistance to the herbicide 2, 4-D in Sisymbrium orientale. bioRxiv. 2021:433944. doi: 10.1101/2021.03.04.433944

Figueiredo, M. R., Leibhart, L. J., Reicher, Z. J., Tranel, P. J., Nissen, S. J., Westra, P., et al. (2018). Metabolism of 2, 4-dichlorophenoxyacetic acid contributes to resistance in a common waterhemp (Amaranthus tuberculatus) population. Pest Manag. Sci. 74, 2356-2362. doi: 10.1002/ps.4811

Gaines, T. A., Duke, S. O., Morran, S., Rigon, C. A., Tranel, P. J., Küpper, A., et al. (2020). Mechanisms of evolved herbicide resistance. J. Biol. Chem. 295, 10307-10330. doi: 10.1074/jbc.REV120.013572

Ghanizadeh, H., and Harrington, K. C. (2020). Perspective: root exudation of herbicides as a novel mode of herbicide resistance in weeds. Pest Manag. Sci. 76, 2543-2547. doi: 10.1002/ps.5850

Gherekhloo, J., Fernández-Moreno, P. T., Alcántara-De La Cruz, R., SánchezGonzález, E., Cruz-Hipolito, H. E., Domínguez-Valenzuela, J. A., et al. (2017). Pro-106-Ser mutation and EPSPS overexpression acting together simultaneously in glyphosate-resistant goosegrass (Eleusine indica). Sci. Rep. 7:1. doi: 10.1038/s41598-017-06772-1

Giacomini, D. A., Patterson, E. L., Küpper, A., Beffa, R., Gaines, T. A., and Tranel, P. J. (2020). Coexpression clusters and allele-specific expression in metabolism-based herbicide resistance. Genome Biol. Evol. 12, 2267-2278. doi: $10.1093 /$ gbe/evaa191

Goggin, D. E., Cawthray, G. R., Flematti, G. R., Bringans, S. D., Lim, H., Beckie, H. J., et al. (2021). Pyroxasulfone-resistant annual ryegrass (Lolium rigidum) has enhanced capacity for glutathione transferase-mediated pyroxasulfone conjugation. J. Agri. Food Chem. 2021:0c07458. doi: 10.1021/acs.jafc.0c07458

Gressel, J. (2009). Evolving understanding of the evolution of herbicide resistance. Pest Manag. Sci. 65, 1164-1173. doi: 10.1002/ps.1842

Hall, L., Holtum, J., and Powles, S. (1994). "Mechanisms responsible for cross resistance and multiple resistance," in Herbicide Resistance in Plants: Biology 
and Biochemistry, eds J. Holtum and S. Powles (Boca Raton, FL: Lewis), 243-262. doi: 10.1201/9781351073189-9

Hall, L. M., Moss, S. R., and Powles, S. B. (1997). Mechanisms of resistance to aryloxyphenoxypropionate herbicides in two resistant biotypes of Alopecurus myosuroides (blackgrass): herbicide metabolism as a cross-resistance mechanism. Pesticide Biochem. Physiol. 57, 87-98. doi: 10.1006/pest.1997.2259

Han, H., Yu, Q., Beffa, R., González, S., Maiwald, F., Wang, J., et al. (2021). Cytochrome P450 CYP81A10v7 in Lolium rigidum confers metabolic resistance to herbicides across at least five modes of action. Plant J. 105, 79-92. doi: $10.1111 /$ tpj.15040

Han, H., Yu, Q., Owen, M. J., Cawthray, G. R., and Powles, S. B. (2016). Widespread occurrence of both metabolic and target-site herbicide resistance mechanisms in Lolium rigidum populations. Pest Manag. Sci. 72, 255-263. doi: $10.1002 /$ ps.3995

Harre, N. T., Young, J. M., and Young, B. G. (2018). Environmental factors moderate glyphosate-induced antagonism of POST herbicides on the rapid response biotype of glyphosate-resistant giant ragweed (Ambrosia trifida). Weed Sci. 66, 301-309. doi: 10.1017/wsc.2017.77

Heap, I. (2021). The International Survey of Herbicide Resistant Weeds. Available online at: www.weedscience.com (accessed May 22, 2021).

Jugulam, M., Dimeo, N., Veldhuis, L. J., Walsh, M., and Hall, J. C. (2013). Investigation of MCPA (4-chloro-2-ethylphenoxyacetate) resistance in wild radish (Raphanus raphanistrum L.). J. Agri. Food Chem. 61, 12516-12521. doi: $10.1021 / \mathrm{jf} 404095 \mathrm{~h}$

Kohlhase, D. R., O'rourke, J. A., Owen, M. D., and Graham, M. A. (2019). Using RNA-seq to characterize responses to 4-hydroxyphenylpyruvate dioxygenase (HPPD) inhibitor herbicide resistance in waterhemp (Amaranthus tuberculatus). BMC Plant Biol. 19, 1-19. doi: 10.1186/s12870-019-1795-x

Leclere, S., Wu, C., Westra, P., and Sammons, R. D. (2018). Cross-resistance to dicamba, 2, 4-D, and fluroxypyr in Kochia scoparia is endowed by a mutation in an AUX/IAA gene. Proc. Natl. Acad. Sci. U. S. A. 115, 2911-2920. doi: 10.1073/pnas.1712372115

Llewellyn, R., Ronning, D., Ouzman, J., Walker, S., Mayfield, A., and Clarke, M. (2016). Impact of Weeds on Australian Grain Production: The Cost of Weeds to Australian Grain Growers and the Adoption of Weed Management and Tillage Practices. Report for Grains Research and Development Corporation (GRDC). Canberra, ACT: Grains Research and Development Corporation (GRDC), 112.

Moretti, M. L., Van Horn, C. R., Robertson, R., Segobye, K., Weller, S. C., Young, B. G., et al. (2018). Glyphosate resistance in Ambrosia trifida: part 2. Rapid response physiology and non-target-site resistance. Pest Manag. Sci. 74, 1079-1088. doi: 10.1002/ps.4569

Neve, P., Sadler, J., and Powles, S. B. (2004). Multiple herbicide resistance in a glyphosate-resistant rigid ryegrass (Lolium rigidum) population. Weed Sci. 52, 920-928. doi: 10.1614/WS-04-007R1

Owen, M., Martinez, N., and Powles, S. (2015). Multiple herbicide resistant wild radish (Raphanus raphanistrum) populations dominate Western Australian cropping fields. Crop Past. Sci. 66, 1079-1085. doi: 10.1071/CP15063

Owen, M. J., Martinez, N. J., and Powles, S. B. (2014). Multiple herbicideresistant Lolium rigidum (annual ryegrass) now dominates across the Western Australian grain belt. Weed Res. 54, 314-324. doi: 10.1111/wre.12068

Palumbi, S. R. (2001). Evolution - humans as the world's greatest evolutionary force. Science 293, 1786-1790. doi: 10.1126/science.293.5536.1786

Pan, L., Yu, Q., Han, H., Mao, L., Nyporko, A., Fan, L., et al. (2019). Aldoketo reductase metabolizes glyphosate and confers glyphosate resistance in Echinochloa colona. Plant Physiol. 19:979. doi: 10.1104/pp.19.00979

Pan, L., Yu, Q., Wang, J., Han, H., Mao, L., Nyporko, A., et al. (2021). An ABCCtype transporter endowing glyphosate resistance in plants. Proc. Natl. Acad. Sci. U. S. A. 118:e2100136118. doi: 10.1073/pnas.2100136118

Peterson, M. A., Collavo, A., Ovejero, R., Shivrain, V., and Walsh, M. J. (2018). The challenge of herbicide resistance around the world: a current summary. Pest Manag. Sci. 74, 2246-2259. doi: 10.1002/ps.4821
Powles, S. B., and Yu, Q. (2010). Evolution in action: plants resistant to herbicides. Ann. Rev. Plant Biol. 61, 317-347. doi: 10.1146/annurev-arplant-042809-112119

Raymond, M., Heckel, D. G., and Scott, J. G. (1989). Interactions between pesticide genes - model and experiment. Genetics 123, 543-551. doi: 10.1093/genetics/123.3.543

Rojano-Delgado, A. M., Portugal, J. M., Palma-Bautista, C., Alcántara-De La Cruz, R., Torra, J., Alcántara, E., et al. (2019). Target site as the main mechanism of resistance to imazamox in a Euphorbia heterophylla biotype. Sci. Rep. 9, 1-11. doi: 10.1038/s41598-019-51682-Z

Schultz, J. L., Chatham, L. A., Riggins, C. W., Tranel, P. J., and Bradley, K. W. (2015). Distribution of herbicide resistances and molecular mechanisms conferring resistance in Missouri waterhemp (Amaranthus rudis Sauer) populations. Weed Sci. 63, 336-345. doi: 10.1614/WS-D-14-0 0102.1

Tardif, F. J., and Powles, S. B. (1994). Herbicide multiple-resistance in a Lolium rigidum biotype is endowed by multiple mechanisms - isolation of a subset with resistant acetyl-CoA carboxylase. Physiol. Plant. 91, 488-494. doi: 10.1111/j.1399-3054.1994.tb02978.x

Tétard-Jones, C., Sabbadin, F., Moss, S., Hull, R., Neve, P., and Edwards, R. (2018). Changes in the proteome of the problem weed blackgrass correlating with multiple-herbicide resistance. Plant J. 94, 709-720. doi: 10.1111/tp j.13892

Torra, J., Rojano-Delgado, A. M., Menéndez, J., Salas, M., and De Prado, R. (2021). Cytochrome P450 metabolism-based herbicide resistance to imazamox and 2, 4-D in Papaver rhoeas. Plant Physiol. Biochem. 160, 51-61. doi: 10.1016/j.plaphy.2021.01.007

Van Horn, C. R., Moretti, M. L., Robertson, R. R., Segobye, K., Weller, S. C., Young, B. G., et al. (2018). Glyphosate resistance in Ambrosia trifida: part 1. Novel rapid cell death response to glyphosate. Pest Manag. Sci. 74, 1071-1078. doi: $10.1002 /$ ps.4567

Vila-Aiub, M. M., Neve, P., Steadman, K. J., and Powles, S. B. (2005). Ecological fitness of a multiple herbicide-resistant Lolium rigidum population: dynamics of seed germination and seedling emergence of resistant and susceptible phenotypes. J. Appl. Ecol. 42, 288-298. doi: 10.1111/j.1365-2664.2005. 01017.x

Walsh, M. J., Powles, S. B., Beard, B. R., and Porter, S. A. (2004). Multiple-herbicide resistance across four modes of action in wild radish (Raphanus raphanistrum). Weed Sci. 52, 8-13. doi: 10.1614/WS-03-016R

Yu, Q., Cairns, A., and Powles, S. (2007). Glyphosate, paraquat and ACCase multiple herbicide resistance evolved in a Lolium rigidum biotype. Planta 225, 499-513. doi: 10.1007/s00425-006-0364-3

Conflict of Interest: The authors declare that the research was conducted in the absence of any commercial or financial relationships that could be construed as a potential conflict of interest.

Publisher's Note: All claims expressed in this article are solely those of the authors and do not necessarily represent those of their affiliated organizations, or those of the publisher, the editors and the reviewers. Any product that may be evaluated in this article, or claim that may be made by its manufacturer, is not guaranteed or endorsed by the publisher.

Copyright (c) 2021 Torra, Osuna, Merotto and Vila-Aiub. This is an open-access article distributed under the terms of the Creative Commons Attribution License (CC $B Y)$. The use, distribution or reproduction in other forums is permitted, provided the original author(s) and the copyright owner(s) are credited and that the original publication in this journal is cited, in accordance with accepted academic practice. No use, distribution or reproduction is permitted which does not comply with these terms. 